\title{
SCIENCE ENROLLMENT AT ELGIN HIGH SCHOOL:
}

\author{
Vilila B. SMrTh, \\ High School, Elgin, Ill.
}

The accompanying graphs, compiled from data on file at Elgin High School, furnish the history of five departments in that institution during the past twenty-two years. The enrollment is expressed in terms of student weeks; that is, if a class of twenty students carries a subject for twenty weeks, the enrollment is considered four-hundred student weeks. In this way it is possible to make comparisons of subjects running each semester with those running the entire year without llagrant error.

All the departments show increased enrollment due to the natural growth of the school. English, however, made greatest progress, changing from second rank in 1897 to first in 1905 and maintaining that place since, Science held fourth place in 1897 and in the years following proved a close competitor with mathematics. In 1917 it outranked mathematics and 1918 found it ranking next to English, and showing every tendency for further advance.

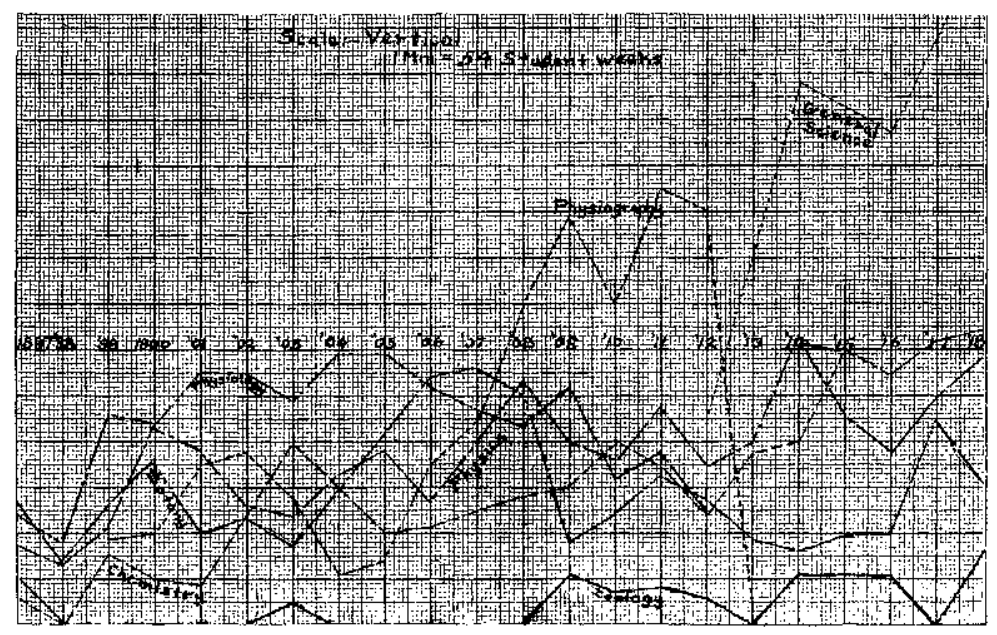

The languages were leaders in 1897 and maintained their place until 1905, then showed a marked decline until 1914, since which time there has been a feeble advance, not sufficient, however, to lift them from the place of lowest rank. History has shown the most uniform growth, and for the past five years has been practically the same.

For this twenty-two year period the individual sciences have 
had an interesting history. Physiology led in 1897, followed by botany, physics, zoology and chemistry. In 1899 physiography was introduced, and for the years 1907-1912 had the greatest enrollment. In 1913 it dropped from the curriculum as a year study; 1912 marked the disappearance of physiology as a semester study.

In 1912 general science was introduced and 1918 found it with an enrollment but fifty less than that of all the other sciences combined. This general science, however, consists of twelve weeks of physiology and twenty-four of modern geography, so represents no new subject matter. That physiology, physiography and general science have been the leaders is entirely due to the fact that they have been the required first-year sciences.

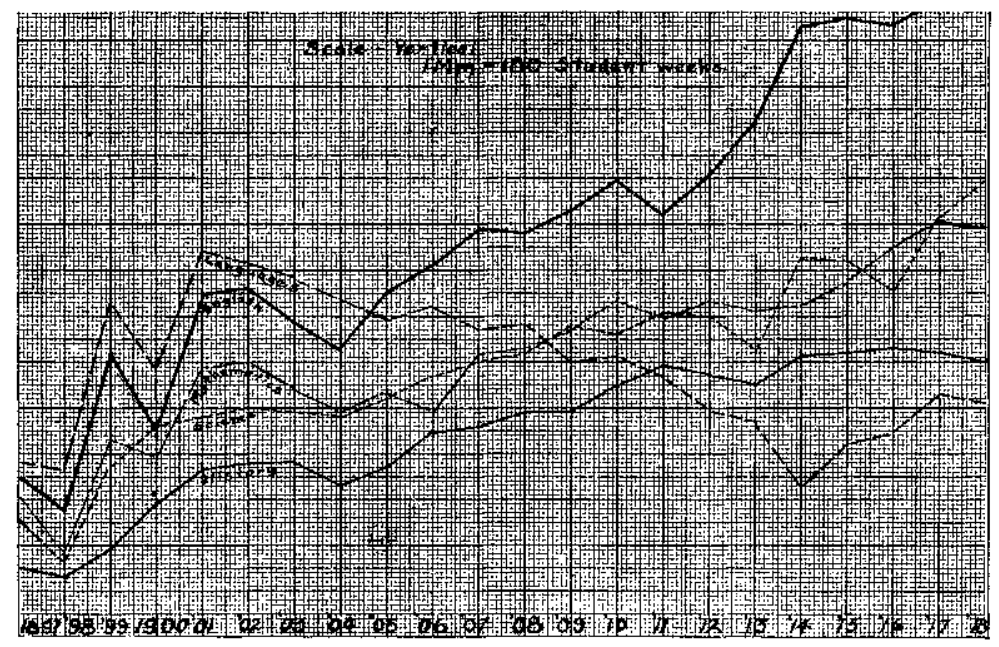

Chemistry enrollment has shown a steady increase, outranking that of physics for the four-year period 1915-1918. At present physics and chemistry are both required for graduation from the four-year science course. The English, general, foreign language and four-year household arts courses require either physics or chemistry, while the manual training course requires physics. As the majority graduate from the general course the choice between chemistry and physics accounts for their popularity.

Botany and zoology are required in both the science and fouryear household arts course, while botany is included among the requirements for the two-year household arts course. For 
the general course, however, with the greatest enrollment, the biological sciences are elective. That in part accounts for their low place among the sciences. Still, should the combined enrollment in botany and zoology be considered, the life sciences rank well with both physics and chemistry. "The fact that there are two to elect from, equalizes the enrollment.

In 1897 of the three courses offered by the school, two required one semester of botany and the third allowed a choice between one year of algebra and a semester each of physiology and botany. In 1900 all the courses required physiology as a first semester study and allowed a choice between botany and physical geography for the second. The 1903 requirements for graduation state specifically, "Students should elect before graduation one of the following: Physics, botany or zoology." In that year botany and zoology were presented as year courses. By 1906, however, botany and zoology are found among the second-year electives.

Domestic science was introduced in 1904 and since that time has had an average annual enrollment of sixty-eight. This course allowed another choice among electives. Its enrollment, however, has not been considered among data here presented.

The foregoing clearly shows that science is not on the decline in Elgin, it ranking well with English, which offers little elective work. Even though the science curriculum has been much enriched, from three and one-half years in 1897 to six in 1918, the consequent greater freedom of election has not caused a decline in any one science.

\section{CRISIS IN THE AMERICAN POTASH INDUSTRY.}

The present is a critical time for the potash industry recently established in the United States, according to H. S. Gale, of the U. S. Geological Survey, Department of the Interior. Prior to the war this country used more than a million tons (gross weight) of potash salts each year, and it has been supposed that the cutting off of a large part of this supply was a keen deprivation, particularly to the farmer, by whom it was used for fertilizer. This foreign supply has not been available during the war, and with much energy and enthusiasm a domestic production equivalent to about one-fourth the former importation has been built up. Now, however, it is unexpectedly disclosed that there is little or no market for potash either at the high prices that have prevailed or even at a considerably lower price. No satisfactory explanation of this situation seems to be offered.

Approximately 100,000 tons (gross weight) of potash salts, produced in Nebraska in 1918, are reported as lying in storage warehouses, distributed. throughout the southeastern States, which is the region where potash is principally consumed. This is of the same quality that was used in 1917 and is immediately available to the fertilizer manufacturer or the farmer. Potash of other sorts from various sourees is also reported unsold. 